\title{
AMELOBLASTIN IS NOT IMPLICATED IN BONE REMODELLING AND REPAIR
}

\author{
Shingo Kuroda ${ }^{1,2}$, Rima Wazen ${ }^{1}$, Karine Sellin ${ }^{1}$, Eiji Tanaka ${ }^{2}$, Pierre Moffatt ${ }^{3}$ and Antonio Nanci ${ }^{1 *}$ \\ ${ }^{1}$ Laboratory for the Study of Calcified Tissues and Biomaterials, Department of Stomatology, Faculty of Dentistry, \\ Université de Montréal, Montréal, Québec, Canada \\ ${ }^{2}$ Department of Orthodontics and Dentofacial Orthopedics, Institute of Health Biosciences, The University of \\ Tokushima Graduate School. Tokushima, Japan \\ ${ }^{3}$ Shriners Hospital for Children, Montréal, Québec, Canada
}

\begin{abstract}
Ameloblastin (AMBN) is an enamel matrix protein produced by ameloblasts. It has been suggested that AMBN might also be implicated in craniofacial bone formation. Our objective was to determine whether AMBN has an effect on osteogenic mineralisation and influences bone remodelling and repair. MC3T3-E1 cells were screened for endogenous expression of enamel proteins using real time PCR. Various osteogenic cells were infected with lentivirus encoding for AMBN and protein expression was verified using immunochemistry. Cultures were stained with alizarin red and mineralisation was quantified. Healing bone was probed for expression of AMBN by DNA microarray analysis. Tooth extraction, experimental tooth movement (ETM), and creation of a non-critical size bone defect in the tibia (BDT) were carried out in wild type and $\mathrm{AMBN}^{\Delta 5-6}$ mutant mice. Tissues were processed for immunolabelling of AMBN and Bril, an osteoblast specific protein associated with active bone formation. MC3T3-E1 cells and healing bone showed no significant expression of AMBN. Overexpression of AMBN in osteogenic cultures induced no noticeable changes in mineralisation. In wild type mice, AMBN was immunodetected in ameloblasts and enamel, but not in normal bone, and at sites where bone remodelling and repair were induced. Bone remodelling during ETM and BDT repair in $\mathrm{AMBN}^{\Delta 5-6}$ mice were not significantly different from that in wild type animals. Our results suggest that $\mathrm{AMBN}$ does not influence osteogenic activity in vitro under the conditions used, and does not participate in craniofacial bone remodelling under mechanical stress and in repair of non-critical size bone defects.
\end{abstract}

Keywords: Ameloblastin, Bril, bone formation, mechanical stress.

*Address for correspondence:

Antonio Nanci

Laboratory for the Study of Calcified Tissues and Biomaterials

Department of Stomatology, Faculty of Dentistry

Université de Montréal, 2900 Edouard Montpetit

Pavillon Roger-Gaudry, Room A-212

H3T1J4 Montréal, Québec, Canada

Telephone Number: $+514-3435846$

FAX Number: +514-3432233

E-mail: antonio.nanci@umontreal.ca
Introduction

Ameloblastin (AMBN) is the second most abundant extracellular matrix protein produced by ameloblasts and is found mainly in forming enamel (Hu et al., 2005). The AMBN gene is classified as a member of the secretory calcium-binding phosphoprotein (SCPP) cluster of evolutionally-related molecules. This cluster is associated with regulation of mineral deposition (Kawasaki and Weiss, 2003). Intact AMBN is short-lived and accumulates at enamel growth sites where enamel crystals elongate (Nanci et al., 1998). In a mutant mouse model expressing a truncated form of AMBN lacking the portion encoded by exons 5 and $6\left(\mathrm{AMBN}^{\Delta 5-6}\right)$, formation of the enamel layer is abrogated (Smith et al., 2009; Wazen et al., 2009).

Recently, expression of AMBN was reported in rat embryos during intramembranous and endochondral ossification (Spahr et al., 2006). Other investigations suggested that the protein has an effect on differentiation of mesenchymal stem cells (Tamburstuen et al., 2010; Tamburstuen et al., 2011), and on osteogenic differentiation (Iizuka et al., 2011). These reports have raised the possibility that AMBN might be implicate not only in amelogenesis but also in osteogenesis.

To test whether AMBN plays a role in bone formation we have (1) used lentiviral vectors to over express the fulllength protein in various osteogenic cells and quantified mineral deposition, and (2) examined bone formation in wild type and $\mathrm{AMBN}^{\Delta 5-6}$ mice following application of mechanical stress in an experimental tooth movement (ETM) model, and in tibia after creation of a non-critical size bone defect (BDT). Bone formation was determined histologically and by immunolabelling for bone-restricted Ifitm-like protein (Bril) (Moffatt et al., 2008), an osteoblast specific membrane protein associated with active bone formation. The results show that AMBN participates neither in mineralisation in osteogenic cell cultures nor in craniofacial bone remodelling under mechanical stress and bone repair in long bones.

\section{Materials and Methods}

All animal procedures were approved by the Comité de déontologie de l'expérimentation sur les animaux of Université de Montréal.

\section{Lentiviral vector production}

Lentivirus encoding for green fluorescent protein (LVGFP) or full-length AMBN (LV-AMBN), under the 
transcriptional control of the EF1-alpha promoter, were produced in human embryonic kidney cell line (HEK293, ATCC, Manassas, VA, USA) as previously reported (Wazen et al., 2006). Lentivirus titers were determined in HEK293 by evaluating the number of AMBN- and GFP-positive cells by fluorescence imaging at $48 \mathrm{~h}$ postinfection and titers ranged from $1 \times 10^{7}$ to $1 \times 10^{8}$ infectious units (IU)/mL.

\section{Cell culture studies MC3T3-E1 and SaOS-2 cells}

The mouse MC3T3-E1 (ATCC CRL-2593) and the human osteosarcoma SaOS-2 cells lines (ATCC HTB-85) were used (Wang et al., 1999; Atkins et al., 2007). Cells were plated on glass cover slips for immunofluorescence analysis (24-well plates, 20,000 cells/well) and directly on plastic for mineralisation assays (6-well plates, 60,000 cells/well) and maintained in $\alpha$-minimal essential medium (alpha-MEM) (Invitrogen, Burlington, ON, Canada) with $10 \%$ foetal bovine serum (FBS), $50 \mu \mathrm{g} / \mathrm{mL}$ ascorbic acid (Sigma-Aldrich, Oakville, Ontario, Canada) and 10 $\mathrm{mM} \beta$-glycerophosphate (Sigma-Aldrich), and medium changed every 3 days.

\section{Cell isolation of rat primary calvaria-derived osteogenic cells}

Osteogenic cells were isolated by sequential trypsin/ collagenase digestion of calvarial bone from newborn (2-4 d) Wistar rats (Charles River, St. Constant, QC, Canada) (Nanci et al., 1996; Irie et al., 1998). Cells were plated on glass cover slips for immunofluorescence analysis (24well plates, 20,000 cells/well) and directly on plastic for mineralisation assays (6-well plates, 60,000 cells/well), and cultured in minimum essential medium with Earle's salts (MEM Earle's) supplemented with $10 \%$ FBS, $1 \%$ penicillin-streptomycin (Invitrogen), $25 \mu \mathrm{g} / \mathrm{mL}$ ascorbic acid and $10 \mathrm{mM} \beta$-glycerophosphate, and medium changed every 3 days.

\section{Real-time PCR analysis of gene expression in MC3T3-E1 cells}

At different time points of cell differentiation (day $1,3,8,15$, and 22 of cell culture), total RNA from MC3T3-E1 cells was extracted using Trizol ${ }^{\circledR}$ (Invitrogen) as recommended by the manufacturer. Total RNA concentration was determined spectrophotometrically at $260 \mathrm{~nm}$ and cDNA prepared using the High Capacity cDNA Reverse Transcription Kit (Applied Biosystems, Foster City, CA, USA). The expression of amelogenin (Amel: Mm00711642_m1), ameloblastin (Ambn: Mm00477485 m1), matrix Gla protein (Mgp: Mm00485009_m1), alkaline phosphatase (Alp: Mm00475834_m1), bone restricted ifitm-like protein (Bril: Mm008047441_g1), osteocalcin (Ocn: Mm03413826_mH) and bone sialoprotein (Ibsp: Mm00492555_m1) was analysed using the indicated TaqMan probes and the TaqMan Universal PCR Master Mix (Applied Biosystems) on an ABI 7500 Real-Time PCR machine. The threshold cycle numbers were normalised to that of beta-actin (TaqMan 4352933E) and values expressed as 2e- $\Delta \mathrm{Ct}$ method (Schmittgen and Livak, 2008). Data are presented on a log scale.

\section{Overexpression of GFP and AMBN in cells infected with lentivirus}

Production of stable cells lines over expressing GFP and AMBN was reported previously (Wazen et al., 2006). For SaOS-2 and primary calvaria-derived cells, at confluency (day 3), cells were infected with the viral vectors using doses ranging from $2.5 \times 10^{5}$ to $4.5 \times 10^{6} \mathrm{IU} / \mathrm{mL}$ in the presence of $8 \mu \mathrm{g} / \mathrm{mL}$ polybrene (Sigma-Aldrich). Both non-infected cells and LV-GFP infected cells were used as controls. After $24 \mathrm{~h}$, the medium was replaced. Forty-eight hours later, the efficiency of transduction was assessed by immunofluorescence (AMBN) and epifluorescence (GFP).

\section{Detection of transgene expression in cells by immunofluorescence}

Forty-eight hours post-infection with LV-AMBN, some cells grown on cover slips were fixed and processed for immunofluorescence labelling with a primary antibody against recombinant rat AMBN (1:300/1 h; courtesy of Dr. Krebsbach) (Krebsbach et al., 1996) followed by a Alexa fluor 594 (red fluorescence)-conjugated goat secondary antibody (1:500/1 h; Molecular Probes, Eugene, OR, USA) (de Oliveira et al., 2003). All cell cultures were mounted with ProLong Gold antifade reagent with 4', 6-diamidine-2'-phenylindole dihydrochloride (DAPI; Invitrogen) to counterstain nuclei in blue, and examined under a fluorescence microscope (Axiophot; Carl Zeiss, Oberkochen, Germany).

\section{Detection of AMBN in Western blotting}

Stable MC3T3-E1 cells over expressing GFP or AMBN were seeded and grown to confluence as mentioned above. Cells were washed and incubated with serum-free media for $72 \mathrm{~h}$. Conditioned media were collected at 24 and $72 \mathrm{~h}$, precipitated with trichloroacetic acid (final concentration $10 \%(\mathrm{v} / \mathrm{v}))$, processed for Western blot analysis under denaturing conditions (Moffatt et al., 2004) and separated on a Ready $\mathrm{Gel}^{\circledR}$ precast $15 \%$ Tris- $\mathrm{HCl}$ polyacrylamide gels (Nanci et al., 1998). Proteins were transferred onto $0.45 \mu \mathrm{m}$ nitrocellulose membranes and probed with AMBN antibody $(1: 2,000)$, all in PBS-0.05\% Tween 20 (Fisher Scientific, Whitby, ON, Canada) with $5 \%$ skim milk. Detection was performed with a secondary goat anti-rabbit antibody IgG-peroxidase conjugate $(1: 30,000 / 1 \mathrm{~h}$; SigmaAldrich), using the ECL plus ${ }^{\text {TM }}$ Western blotting detection system (GE Amersham Biosciences, QC, Canada) as per recommendations by the manufacturer. Broad range molecular weight protein markers (Bio-Rad) were also loaded.

\section{Detection and quantification of mineralisation}

At day 7 (primary calvaria-derived cells), day 9 (SaOS-2) and day 21 (MC3T3-E1), cultures $(n=6)$ from non-infected control, GFP-infected control and AMBN-infected groups were briefly rinsed with PBS followed by fixation with $70 \%$ ethanol for $1 \mathrm{~h}$ at $4{ }^{\circ} \mathrm{C}$. Cultures were washed with distilled water and stained for $10 \mathrm{~min}$, at room temperature, with a $2 \%(\mathrm{w} / \mathrm{v})$ alizarin red solution ( $\mathrm{pH} 4.2$, Sigma-Aldrich), and then rinsed 5 times with water to remove nonspecific stain. Stained cultures of primary calvaria-derived and 


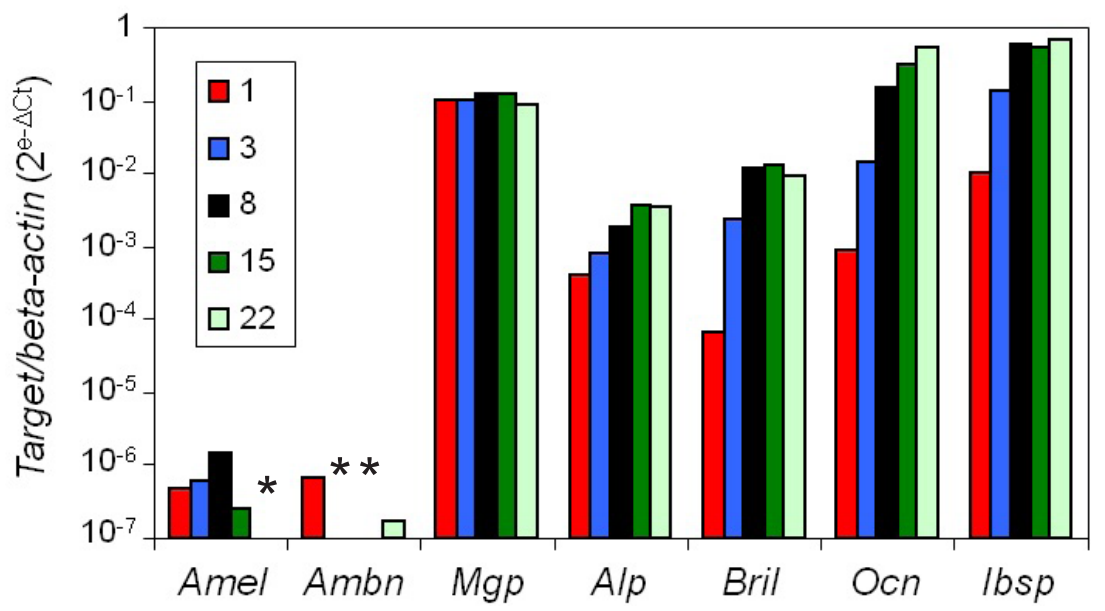

Fig. 1. Quantitative real time PCR analysis of MC3T3-E1 osteogenic cells cultured in osteogenic media for 1, 3, 8,15 and 22 days. The values are plotted on a logarithmic scale and show that the level of expression of enamel matrix proteins (Ambn and Amel) was at least 3-orders of magnitude lower than that of bone-specific markers and near detectability limit. Alp, alkaline phosphatase; Amel, amelogenin; Ambn, ameloblastin; Bril, bone restricted ifitm-like protein; Ibsp, bone sialoprotein; Mgp, matrix Gla protein; Ocn, osteocalcin; *, not detectable.

SaOS-2 cells were photographed and then destained using $10 \%(\mathrm{w} / \mathrm{v})$ cetylpyridinium chloride (SigmaAldrich) in $10 \mathrm{mM}$ sodium phosphate, $\mathrm{pH} 7.0$, for 15 min, at room temperature (Stanford et al., 1995). Calcium concentrations were then determined by the absorbance measured at $570 / 620 \mathrm{~nm}$ on a microplate reader AD340 (Beckman Coulter Inc., Brea, CA, USA). Mineralisation was estimated histomorphometrically in alizarin red stained cultures of MC3T3-E1 cells using analySIS ${ }^{\circledR}$ software (Soft Imaging System GmbH, Lakewood, CO, USA). One-way analysis of valiance (ANOVA) was used to evaluate the differences among the 3 groups. A probability of $p<0.05$ was considered significant.

\section{Animal experimental procedures}

Twelve AMBN ${ }^{\Delta 5-6}$ mice and 17 wild type C57Bl/ 6 mice weighting $25 \pm 5 \mathrm{~g}$ (Charles Rivers) were used. The original AMBN mutant mouse model was created and obtained from Dr. Yamada (Fukumoto et al., 2004). Genotyping was done by PCR analysis of genomic DNA extracted from mouse tail clips as described by Wazen et al. (2009).

Animals were anaesthetised with an intraperitoneal injection of a mixture of $50 \mathrm{mg} / \mathrm{kg}$ of ketamine hydrochloride (Ketaset ${ }^{\circledR}$; Wyeth Canada, St. Laurent, QC, Canada), 5 $\mathrm{mg} / \mathrm{kg}$ of xylazine (Rompun ${ }^{\circledR}$; Bayer Inc., Toronto, ON, Canada) and $1 \mathrm{mg} / \mathrm{kg}$ of acepromazine maleate (Acevet $10^{\circledR}$; Vétoquinol, Lavaltrie, QC, Canada). In a preliminary study aimed at examining AMBN and Bril expression in actively-forming bone, the maxillary left first molar of wild type mice was extracted with an excavator, and sacrificed 5 days after extraction. For ETM, nickeltitanium wire, 0.012 inches $(304.8 \mu \mathrm{m})$ in diameter, was fixed to the maxillary incisor by means of a composite resin for orthodontic bonding (Transbond ${ }^{\circledR}$; 3M Unitek, St. Paul, MN, USA), and the left maxillary 1st molar was moved toward the palatal side with $10 \mathrm{~g}$ load as described previously, while the untreated contralateral teeth served as control (Sakai et al., 2009). For BDT, an incision was made over the left anterior-proximal tibia, and a hole was drilled mono-cortically with a high-speed dental engine (20,000 rpm) using a $1.0 \mathrm{~mm}$ carbide bar (Brasseler USA, Savannah, GA, USA). A resorbable collagen membrane (neomem $^{\circledR}$, Citagenix Inc., Laval, QC, Canada) was placed to cover the hole for reducing blood flow from the wound. Finally, wounds were closed with metal clips. Following experimental manipulations, animals received an injection of buprenorphine hydrochloride (Temgesic ${ }^{\circledR}$; Reckitt and Colman, Hull, UK).

\section{Tissue processing for histology}

Animals were anaesthetised with $20 \%$ chloral hydrate solution $(0.4 \mathrm{mg} / \mathrm{g}$ body weight; Fisher Scientific) and ketamine hydrochloride $(10 \mathrm{mg} / \mathrm{kg})$ and sacrificed by perfusion through the left ventricle with Ringer's lactate (Hospira, Montreal, QC, Canada) for $30 \mathrm{~s}$, followed by a fixative solution consisting of $4 \%$ paraformaldehyde (Acros organics, Morris Plains, NJ) and $0.1 \%$ glutaraldehyde (Electron Microscopy Sciences, Washington, PA, USA) in $0.08 \mathrm{M}$ sodium cacodylate (Electron Microscopy Sciences) buffer containing $0.05 \%$ calcium chloride (JT Baker, Phillipsburg, NJ, USA), pH 7.2, for 20 min. For tooth extraction studies, animals were sacrificed at day 5 post-surgery. For BDT and ETM, mice were sacrificed at days 5, 7 and 14 after the procedure (Nanci et al., 2004). Maxillae and tibiae were dissected, and specimens were immersed in the same fixative solution overnight at $4{ }^{\circ} \mathrm{C}$ and decalcified with Plank-Rychlo's solution consisting of $0.5 \mathrm{M}$ aluminium chloride (Sigma-Aldrich) containing $8.5 \%$ hydrochloric acid (Fisher Scientific) and $5.4 \%$ formic acid (JT Baker) for 7 days at $4{ }^{\circ} \mathrm{C}$ (Schroeder, 1991). Decalcified samples were washed for $24 \mathrm{~h}$ in $0.1 \mathrm{M}$ sodium cacodylate buffer, $\mathrm{pH} 7.2$, processed for paraffin embedding and sectioned at $5 \mu \mathrm{m}$ thickness. For morphological analyses, sections were stained with haematoxylin and eosin. 


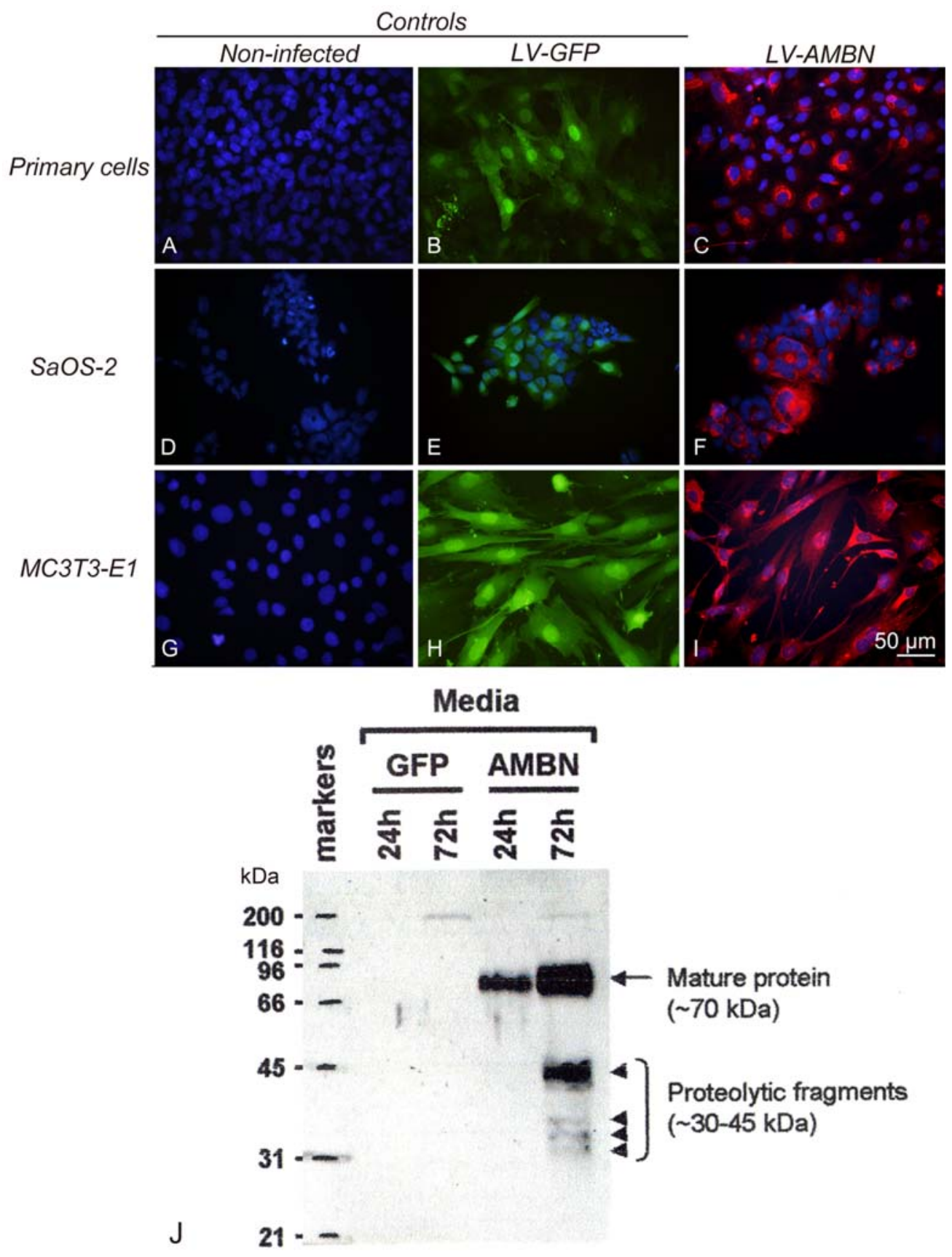

Fig. 2. Expression of AMBN and GFP in lentivirus-transduced primary rat calvaria-derived osteogenic cells (A-C), human SaOS-2 (D-F) and mouse MC3T3-E1 (G-I) cells, at $48 \mathrm{~h}$ post-infection, with an infectious unit of $4.5 \times 10^{5}$, $4.5 \times 10^{6}$ and $2.5 \times 10^{5} \mathrm{IU} / \mathrm{mL}$, respectively. GFP expression is distributed throughout the cytoplasm (B, E, H), while AMBN is immunolocalised in the perinuclear region of the cells where the Golgi is found (C, F, I). Non-infected cells were used as controls and did not show any labelling for $\operatorname{AMBN}(\mathbf{A}, \mathbf{D}, \mathbf{G})$. Western blot detection of $A M B N$ produced by MC3T3-E1 cells (J). AMBN-specific bands were only visible in conditioned media of AMBN over expressing cells at $24 \mathrm{~h}$ and $72 \mathrm{~h}$.

Tissue processing of healing bone for DNA microarray analysis of gene expression of osteogenic molecules

At day 3, some animals of the BDT experimental group $(\mathrm{n}=5)$ were anaesthetised, and the bone at the defect site was harvested using a trephine drill (2 mm diameter, ACE Dental Implant System, Brockton, MA, USA) fitted on a slow-speed handpiece (Physiodispenser 3000, Henry Schein Inc., Niagara On The Lake, ON, Canada), placed in Trizol $^{\circledR}$ (Invitrogen) and immediately homogenisation with the Polytron ${ }^{\circledR}$ (Kinematic Inc., Bohemia, NY, USA) at full speed for $1 \mathrm{~min}$. Total RNA was extracted from the samples as recommended by manufacturer and purified with the RNeasy $^{\circledR}$ MiniElute $^{\circledR}$ Cleanup kit (Qiagen, Mississauga, ON, Canada). The extracted cRNA was hybridised with the mouse Oligo GEarray ${ }^{\circledR}$ (SuperArray Bioscience, Frederick, MD, USA) as recommended by the manufacturer. This array contains the cDNA for various osteogenic molecules as well as for AMBN. 
A

Primary cells

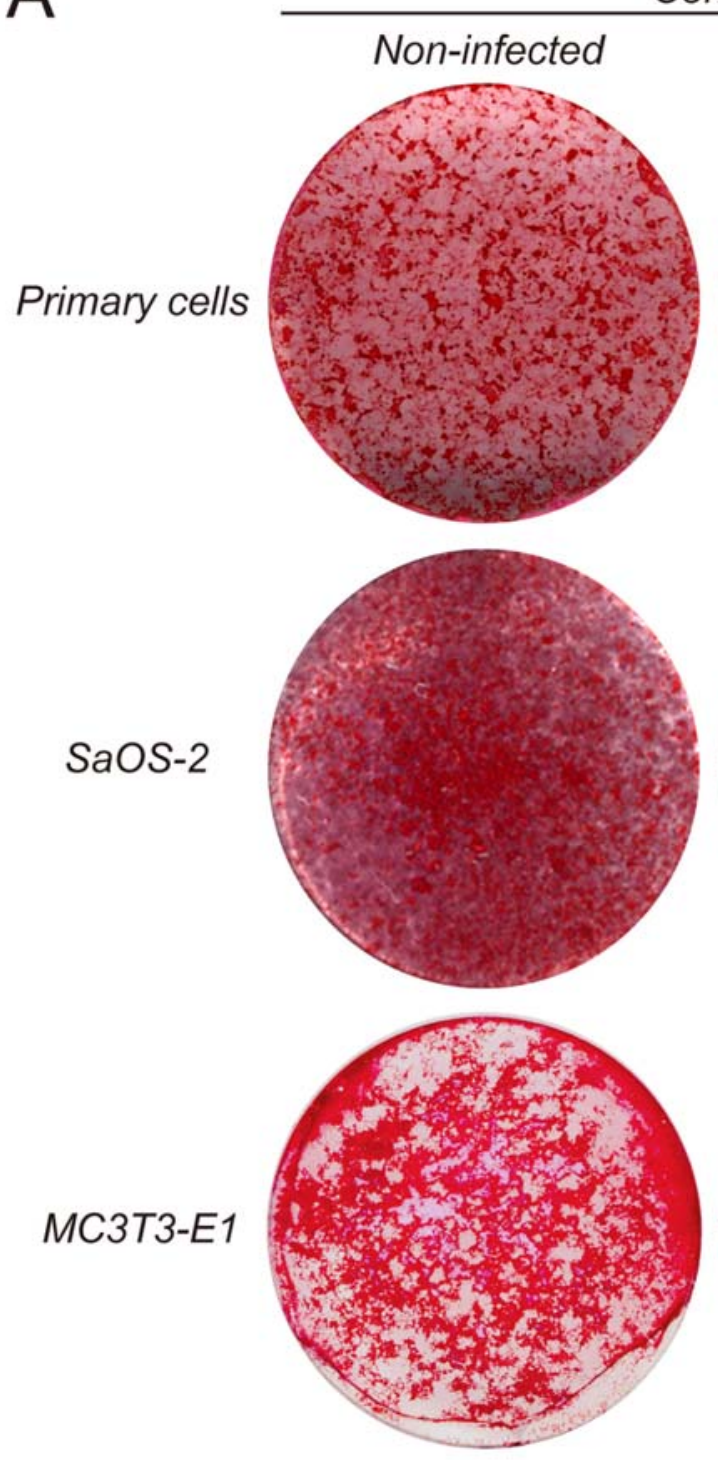

\section{Controls}
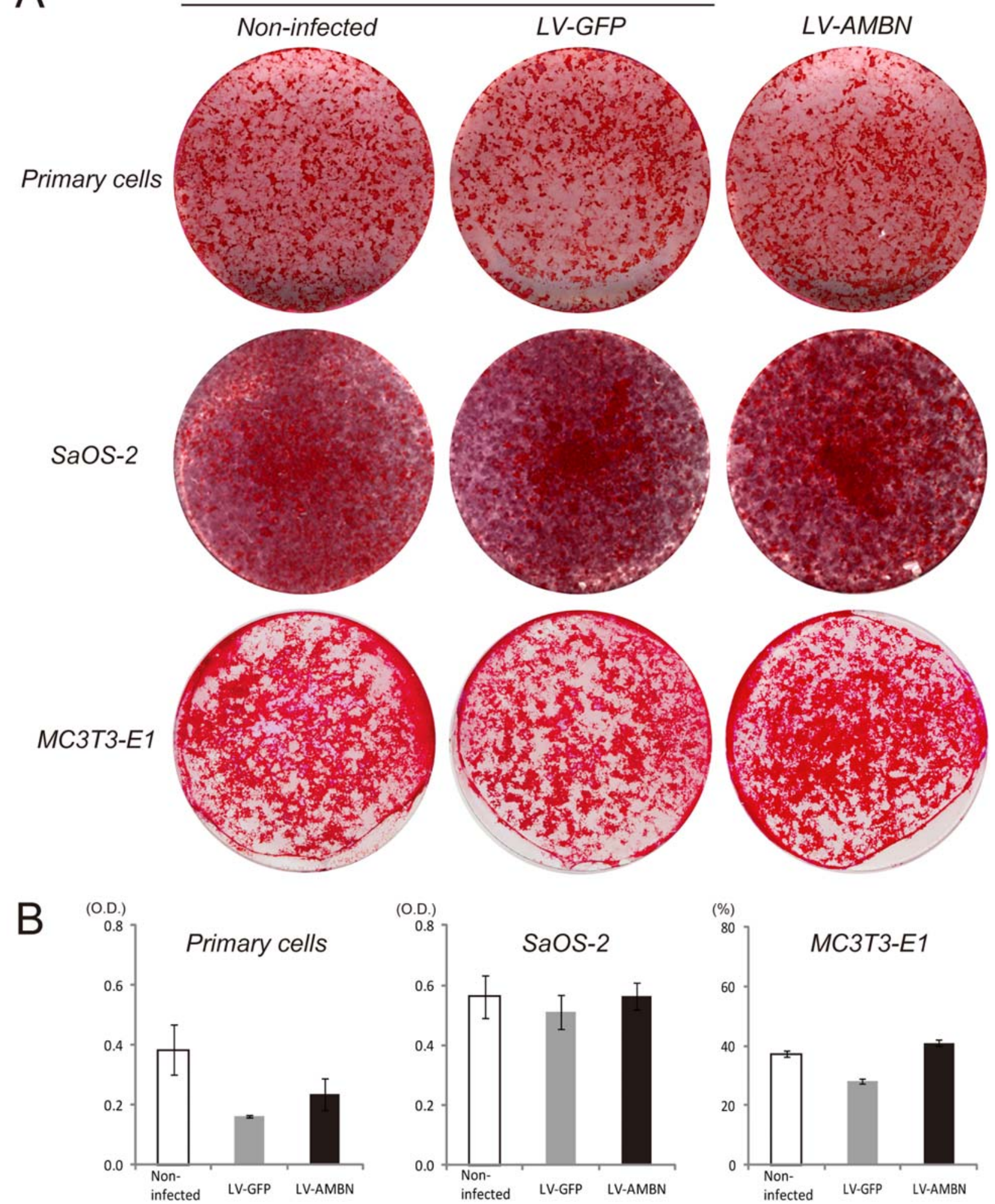

Fig. 3. Lentivirus-mediated expression of AMBN did not have an effect on the mineralisation of primary rat calvaria-derived osteogenic cells, human SaOS-2 and mouse MC3T3-E1 cells. Cell cultures were infected with the lentivirus, stopped at day 7,9 and 21, respectively, and analysed for mineralisation by alizarin red staining (A). Controls consisted of non-infected cells and LV-GFP infected cells. Quantification of mineralisation (primary cells and SaOS-2) and histomorphometric analyses (MC3T3-E1) did not reveal any significant differences in the mineralisation process of AMBN-overexpressing osteogenic cell cultures (B). O.D., optical density at 570/620 nm. 


\section{Immunohistochemistry}

Sections were deparaffinised with d-limonene based solvent (Citrisolv ${ }^{\circledR} ;$ Fisher Scientific), rehydrated through a descending ethanol series and washed in distilled water. In order to avoid non-specific sticking, sections were blocked with $0.01 \mathrm{M}$ phosphate-buffered saline (PBS), $\mathrm{pH}$ 7.4, containing $5 \%$ skim milk for $30 \mathrm{~min}$ at room temperature. After blocking, the sections were incubated with a primary antibodies to AMBN $(1: 2,000)$ or Bril $(1: 2,000)$ (Moffatt et al., 2008) for $3 \mathrm{~h}$ at room temperature. Sections were washed with $0.01 \mathrm{M}$ PBS containing $0.05 \%(\mathrm{v} / \mathrm{v})$ Tween 20, followed by treatment with the Envision TM+System, HRP labelled polymer anti-rabbit kit (Dako, Carpinteria, CA, USA) as recommended by the manufacturer. Visualisation was performed with 3, 3'-diaminobenzidine and sections were counterstained with $0.5 \%$ methyl green (Dako).

\section{Results}

\section{Effect of AMBN on mineralisation in vitro}

Quantitative real time PCR analysis was used to investigate the endogenous level of expression of enamel matrix proteins (Amel and Ambn) in MC3T3-E1 cells cultured in osteogenic media (Fig. 1). At any time-points of cell culture, expression of Amel and Ambn was at least 3-orders of magnitude lower than that of bone-specific markers (Mgp, Alp, Bril, Ocn and Ibsp), and near detection limit.

In stably over expressing MC3T3-E1 cell cultures and $48 \mathrm{~h}$ post-infection ( $\mathrm{SaOS}-2$, primary osteogenic cells), GFP expression was immunodetected throughout the cell, including the nucleus (Figs. 2B, E, and H) whereas AMBN was found in the perinuclear region where the Golgi apparatus is found (Figs. 2C, F, and I). Immunoreactivity for AMBN was not detected in control primary osteogenic cells, MC3T3-E1 and SaOS-2 cells (Figs. 2A, D, and G). Secretion of AMBN by MC3T3-E1 cells was readily detected with Western blots and significantly increased in a time-dependent manner (Fig. 2J). Histomorphometric analysis of alizarin red staining and quantification of mineralisation, however, indicated that over expression of AMBN had no noticeable effect on osteogenic mineralisation in the 3 cell types examined, as compared to the non-infected control cells or the LV-GFP infected cells (Fig. 3).

\section{AMBN is not implicated in bone formation in various animal models}

In wild type mice, AMBN was clearly immunodetected in enamel and ameloblasts from presecretion to the maturation stage of amelogenesis (Fig. 4A), consistent with our previous work (Nanci et al., 1998; Wazen et al. 2009). At day 5 after tooth extraction, AMBN was not expressed in the alveolar bone at the tooth extraction site (Fig. 4B), which intensely showed Bril immunolabelling (Fig. 4C).

Gene profiling using DNA microarrays revealed no detectable expression of Ambn in healing bone (position \#4 on the array) (Fig. 5).

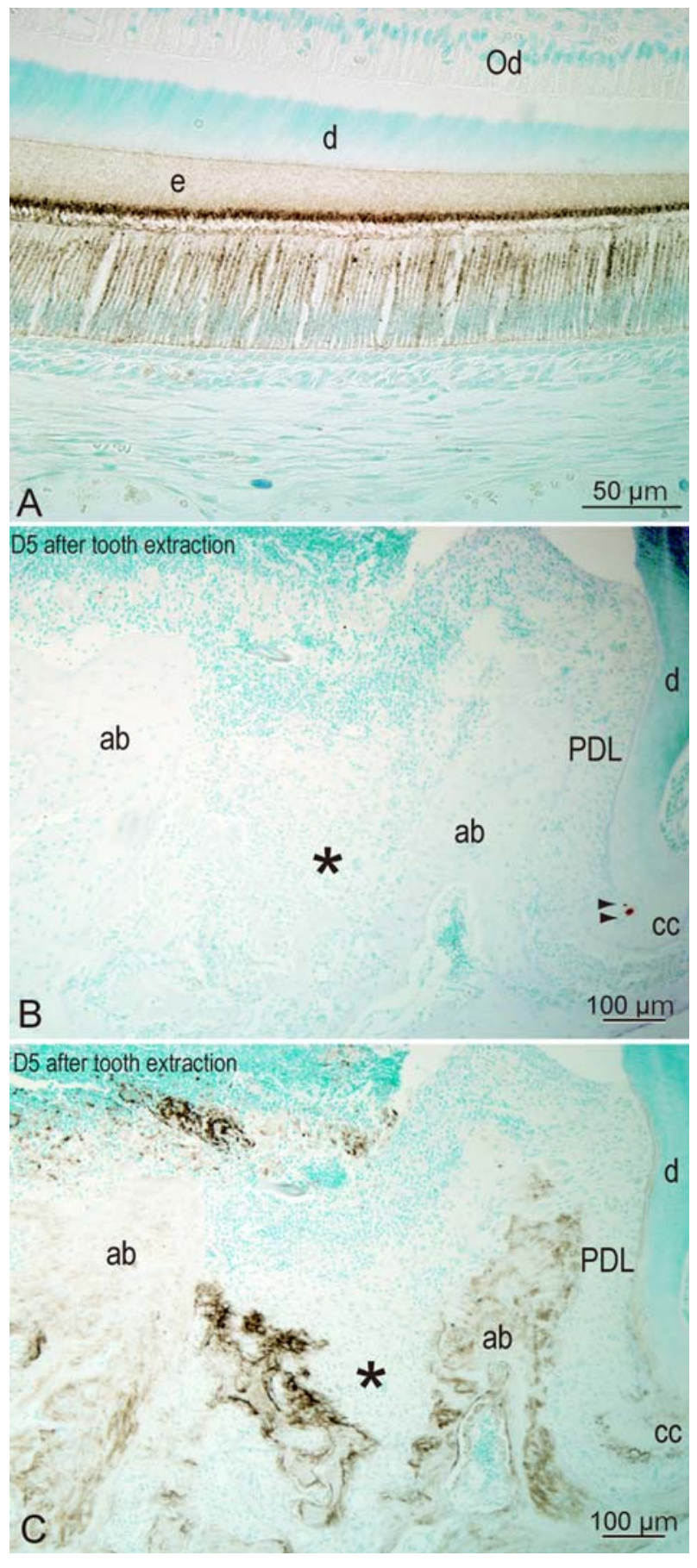

Fig. 4. Immunolabelling of AMBN and Bril in the periodontal tissue. (A) Immunolabelling for AMBN was clearly detected in secretory stage ameloblasts in the maxillary incisor. (B) Five days (D5) after extraction of the maxillary first molar, expression of AMBN was only detected in few cells entrapped in cellular cementum (cc) at the root apex (arrowheads), but not in the alveolar bone (ab), including newlyformed bone at the extraction site (asterisk). (C) In a serial section of (B), there was an intense expression of Bril indicating active bone formation at the extraction site. e, enamel; d, dentin; Od, odontoblasts; PDL, periodontal ligament. 
In order to study the expression pattern of AMBN under mechanical stimulus, a nickel-titanium wire placed on the maxillary incisor provided sufficient orthodontic force to tip the first molar towards the palate. The width of periodontal ligament was decreased on the compression area and increased on the tension area (Figs. 6B and J). At day 5 and 7, as judged by the abundance of osteoclasts, bone resorption was observed on the compression area (Figs. 6C and K). At day 14, the width of periodontal ligament on both the compression and tension areas was back to the normal range (Figs. 6D and L). These morphological changes were similar in wild type and $\mathrm{AMBN}^{\Delta 5-6}$ mice.

In order to examine active bone formation, we performed immunolabelling for Bril. On the untreated side, expression of Bril was observed in the cells on the surface of alveolar bone and cementum on the mesial side from the cervical to the apical extremity of the root (Figs. 6E and M). At day 5 and 7 after ETM, Bril was immunodetected in the cells on the surface of the alveolar bone and facing cellular cementum on the tension area, where new tissues actively form (Figs 6F, G, N, and O). At day 14, expression of Bril was also present in the cells on the surface of alveolar bone and cementum on the compression area (Figs $6 \mathrm{H}$ and $\mathrm{P}$ ). There was no difference in Bril expression pattern between the wild type and AMBN mutant mice. There was also no difference in AMBN expression, as its labelling was observed in cellular cementum but not in the alveolar bone, at any time points examined (Figs. 6Q-T).

In the BDT model, at day 5 after surgery, in wild type mice healing was evident at the periphery of the defect, and the newly-formed bone was labelled for Bril (Figs. 7D and J). At day 7, bone formation had extended toward the centre of the defect, and this bone was more immunoreactive than the older peripheral bone (Figs. 7E and $\mathrm{K}$ ). By day 14, the defect was almost filled up with new bone and Bril expression was lower throughout (Figs. 7F and $\mathrm{J}$ ). This time-dependent pattern of bone regeneration and Brill expression was similar in $\mathrm{AMBN}^{\Delta 5-6}$ mice. Also, at all time intervals examined, there was no reactivity for AMBN in the healing bone under the tissue processing and incubation conditions used (Figs. 7M-O).

Incubations with pre-immune serum and omission of primary antibody only resulted in background labelling throughout the tissue section (data not shown).

\section{Discussion}

There have been some recent reports suggesting that AMBN may be involved in bone formation (Tamburstuen et al., 2010; Tamburstuen et al., 2011; Iizuka et al., 2011) and that, like its sister protein AMEL, it may be capable of promoting bone repair (Bosshardt, 2008; Haze et al., 2009). To test this possibility, we have evaluated the effect of AMBN on bone formation both in vitro and in various animal models. Taken together, the results indicate that AMBN is not involved in mechanically-induced bone formation and in repair of non-critical size bone defects. It should be noted here that under experimental conditions known to reveal the presence of $\mathrm{AMBN}$, the protein has

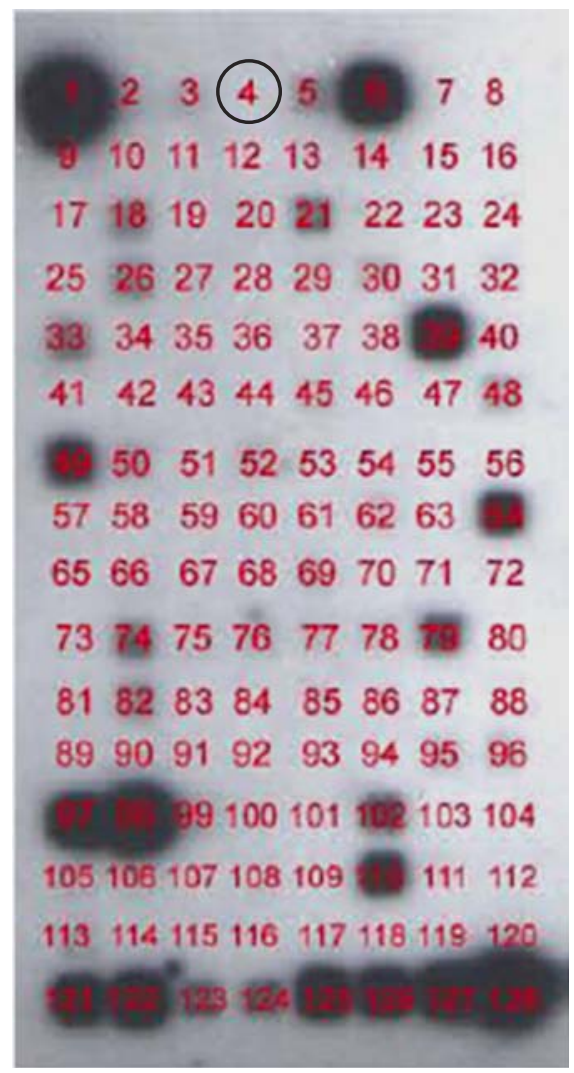

Fig. 5. DNA microarray analysis of gene expression for osteogenic molecules in healing bone three days postsurgery. Position 4 corresponds to the AMBN cDNA; no signal is evident.

so far not been immunodetected in bone after post-natal day 28 (Spahr et al., 2006). We, similarly, have not been able to immunodetect AMBN in normal bone around the experimental sites. Real time PCR and DNA microarray analyses also showed no significant expression of AMBN. Whole genome analyses of tibial healing bone similarly showed no significant expression of enamel proteins, including Amel and Ambn (unpublished data).

While EDTA decalcification may lead to extraction of some proteins in bone, thereby affecting detectability, it was shown that fixation efficiently retains various noncollagenous matrix proteins (McKee et al., 1991). With respect to molecular biology, samples were left calcified and the quality of the RNA verified. It is thus unlikely that the detection of AMBN was altered. Furthermore, $\mathrm{AMBN}^{\Delta 5-6}$ mice in which enamel formation is abrogated showed no evident defect in bone development (Fukumoto et al., 2004; Wazen et al., 2009). Hence, it can be concluded that $\mathrm{AMBN}$ is not needed for normal physiological bone formation.

Overexpression of $\mathrm{AMBN}$ in both primary and transformed osteogenic cells did not result in significant changes in mineral deposition. While it cannot be excluded that the level of expression may be a limiting factor, the cells showed immunolabelling patterns typical of actively synthesising cells, and the protein was clearly secreted and accumulated in the culture medium. Iizuka et al. 


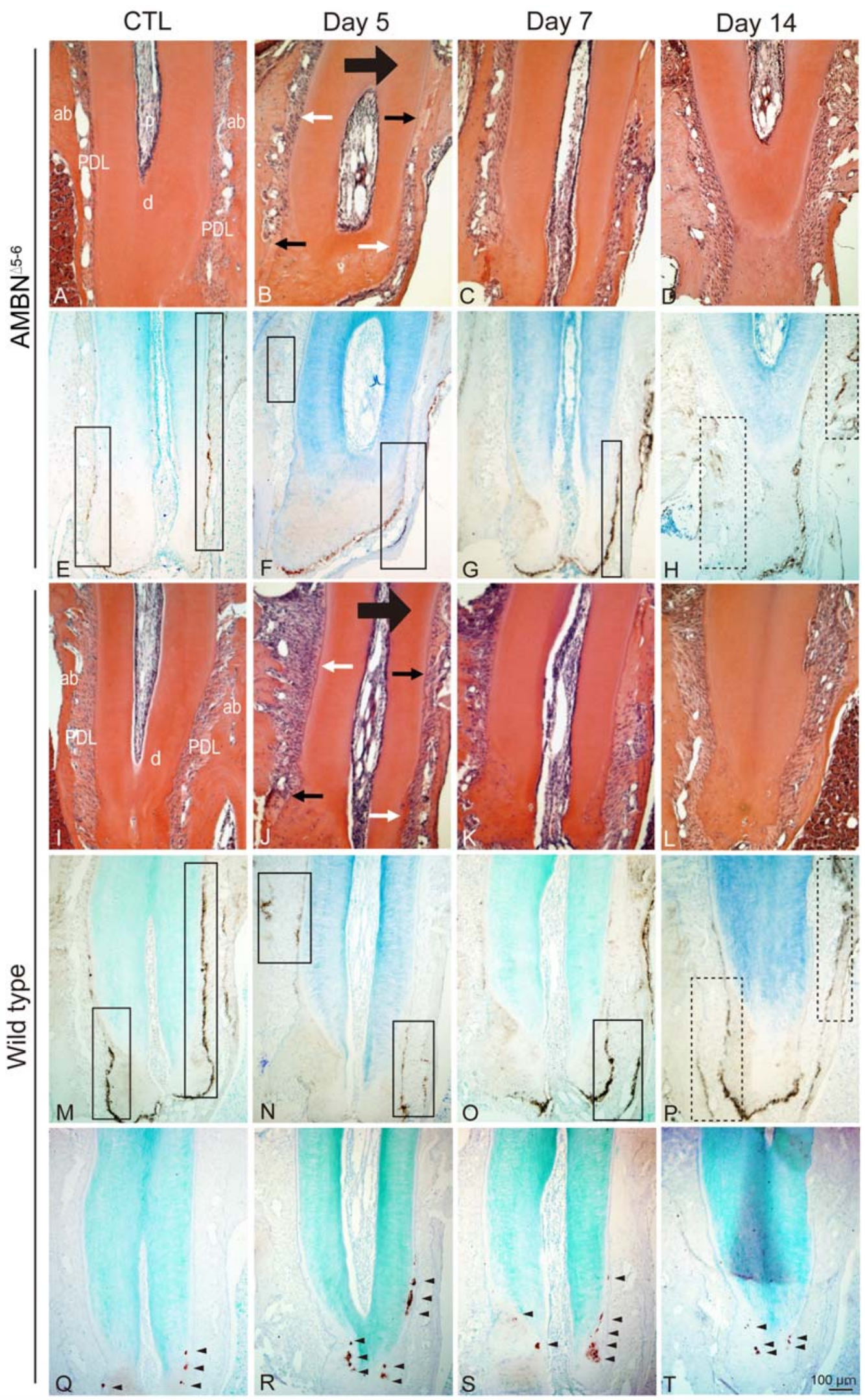

Fig. 6. Expression of Bril and $A M B N$ during periodontal tissue remodelling in $\mathrm{AMBN}^{\Delta 5-6}$ and WT mice. Immunolabelling of Bril (E-H, M-P) and AMBN (Q-T) and haematoxylin-eosin staining (A-D, I-L) are shown. When the mechanical stress was applied to the tooth toward the palate (large black arrow), the width of periodontal ligament (PDL) was decreased on the compression areas (black arrows) and increased on the tension areas (white arrows) (B, J). Immunolabelling for Bril was shown in cells on the surface of alveolar bone (ab) and cementum on the tension areas (boxed areas) at days 5 and 7 and control subjects (E-G, M-O). At day 14, Bril expression was present on the surface of alveolar bone on the compression areas $(\mathbf{H}, \mathbf{P}$, boxed areas with dotted border). In WT mice, AMBN was only detected in the cellular cementum (Q-T, arrowheads). d, dentin. 


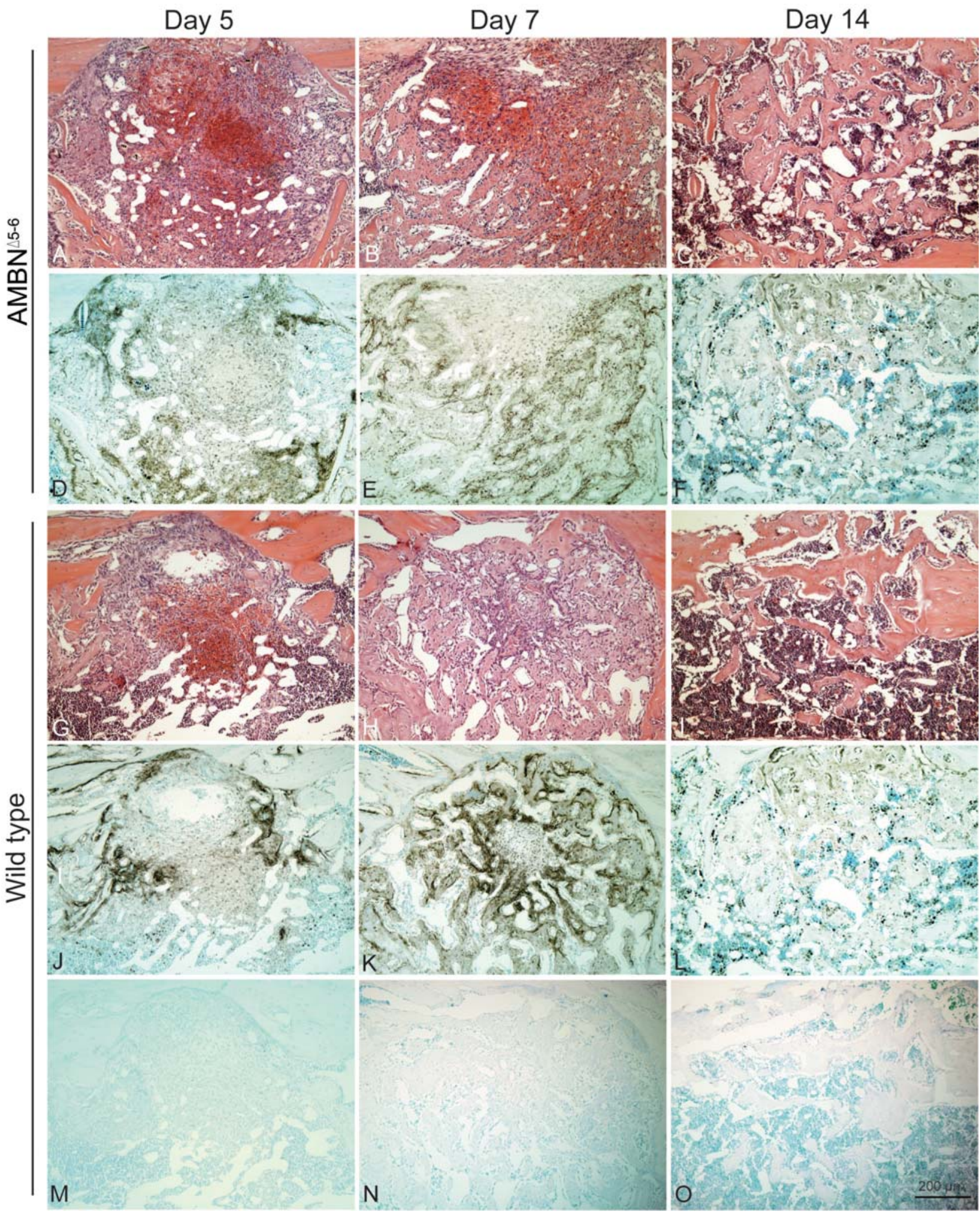

Fig. 7. Expression of Bril and $A M B N$ in the tibial bone defects in $A M B N^{\Delta 5-6}$ and $W T$ mice. Immunolabelling of Bril (D-F, J-L) and AMBN (M-O) and haematoxylin-eosin staining (A-C, G-J) are shown. Bone formation started at day 5 and the defect was almost completely repaired by day 14 (A-C, G-H). Bril expression started from the bone surrounding the defect at day 5 after surgery (D, J). Its expression became more intense toward the centre of the defect at day $7(\mathbf{E}, \mathbf{K})$, and was diminished at day 14 (F, I). The temporal patterns of Bril expression and of bone regeneration in $\mathrm{AMBN}^{\Delta 5-6}$ mice corresponded to those in wild type mice. AMBN expression was not detected in the defect at any time points of healing (M-O). 
(2011) have reported that expression of CD63 is essential for AMBN activity. The MC3T3-E1 cell line used in this study expresses CD63 but the SaOS-2 cell line does not (unpublished), yet no effect on mineral nodule formation was detected with both cell lines. Since positive expression of CD63 has been reported in both cell lines (Pereira et al., 2009; Shapiro et al., 2007), discrepancies in results could be explained by the source of cell lines used and/or cell transformation following multiple passages.

We used Bril as a marker of bone formation. In vitro functional analyses reveal that expression of Bril increases with osteoblast differentiation, peaking with matrix production and bone mineralisation (Moffatt et al., 2008). This osteoblastic protein is also conspicuously present along bone surfaces where there is active formation (Moffatt et al., 2008). The enhancement of Bril expression, when new bone formation is induced mechanically or in situations of bone repair, validates the use of Bril for evaluating osteogenesis. Both during ETM and BDT, the expression pattern of Bril in $\mathrm{AMBN}^{\Delta 5-6}$ and wild type mice was very similar. Since bone formation progresses in the same manner in both normal and mutant mice, AMBN is not needed for bone remodelling in craniofacial bone under mechanical stress and for repair of bone defects in long bones in mice.

Spahr et al. (2006) initially reported the expression of AMBN in rat embryo bone, using immunohistochemistry and in situ hybridisation, and proposed that AMBN participates in bone development. On the other hand, they also showed that expression decreased markedly with time and disappeared after completion of bone modelling (Spahr et al., 2006), suggesting no involvement in the physiologic maintenance of adult bone. While no impairment of bone formation is evident in the AMBN mutant mice (Wazen et al., 2009), recent studies - also reported by Fukumoto et al. (2004) - suggested a positive role for AMBN in bone generation in vivo and in vitro (Tamburstuen et al., 2010; Tamburstuen et al., 2011; Iizuka et al., 2011). Tamburstuen et al. (2010) showed the expression of AMBN mRNA and protein secretion in human mesenchymal stem cells, primary osteoblasts and chondrocytes. They also demonstrated, using a microarray technique, that the genes related to immune responses, expression of cytokines and markers of osteogenic cell differentiation were upregulated by the application of recombinant AMBN in cell culture (Tamburstuen et al., 2011). Iizuka et al. (2011) concluded, in their in vitro investigation of sarcoma cell lines, that AMBN was expressed in osteoblasts and acted as a promoting factor for osteogenic differentiation via a pathway through the interaction between CD63 and integrin $\beta 1$. Tamburstuen et al. (2010) also claimed that recombinant $\mathrm{AMBN}$ induced new bone formation in their bone defect model. While our results differ, they do not rule out the possibility that AMBN might be implicated in embryonic bone development. Indeed, the bone-active portion of the molecule could be positioned on the portion of the molecule expressed in the mutant (Wazen et al., 2009). A full-knockout is needed to address this question. Another possibility is that compensatory mechanisms kick-in to make up for the defective AMBN molecule. This is a plausible scenario when considering that substantial cellular and molecular factors are involved in bone remodelling processes, and bone is a vital tissue/organ without which life as we know would not be possible (Raggatt and Partridge, 2010).

In conclusion, our results suggest that AMBN does not influence osteogenic activity in vitro, under the expression conditions used, and does not participate in craniofacial bone remodelling under mechanical stress and in repair of non-critical bone defects in long bones. While AMBN does not appear to have a role in physiological bone formation, it cannot be excluded that it may be advantageously exploited pharmacological for tissue repair and healing. This is indeed the case for AMEL (Bosshardt, 2008; Haze et al., 2009), another enamel matrix protein which has evolved from a common ancestor with AMBN (Sire et al., 2007). While our in vitro results are not conclusive on this aspect, animal studies as initiated by Tamburstuen et al. (2010) are needed to unequivocally address the possibility of a pharmacological effect.

\section{Acknowledgements}

We extend our thanks to Ms Cynthia Török for technical assistance. This study was supported by the Canadian Institutes of Health Research. Pierre Moffatt is supported by the Shriners of North America.

\section{References}

Atkins GJ, Anderson PH, Findlay DM, Welldon KJ, Vincent C, Zannettino AC, O'Loughlin PD, Morris HA (2007) Metabolism of vitamin D3 in human osteoblasts: evidence for autocrine and paracrine activities of 1 alpha,25-dihydroxyvitamin D3. Bone 40: 1517-1528.

Bosshardt DD (2008) Biological mediators and periodontal regeneration: a review of enamel matrix proteins at the cellular and molecular levels. J Clin Periodontol 35 (8 Suppl): 87-105.

de Oliveira PT, Zalzal SF, Irie K, Nanci A (2003) Early expression of bone matrix proteins in osteogenic cell cultures. J Histochem Cytochem 51: 633-641.

Fukumoto S, Kiba T, Hall B, Iehara N, Nakamura T, Longenecker G, Krebsbach PH, Nanci A, Kulkarni AB, Yamada Y (2004) Ameloblastin is a cell adhesion molecule required for maintaining the differentiation state of ameloblasts. J Cell Biol 167: 973-983.

Haze A, Taylor AL, Haegewald S, Leiser Y, Shay B, Rosenfeld E, Gruenbaum-Cohen Y, Dafni L, Zimmermann B, Heikinheimo K, Gibson CW, Fisher LW, Young MF, Blumenfeld A, Bernimoulin JP, Deutsch D (2009) Regeneration of bone and periodontal ligament induced by recombinant amelogenin after periodontitis. J Cell Mol Med 13: 1110-1124.

$\mathrm{Hu}$ JC, Yamakoshi Y, Yamakoshi F, Krebsbach PH, Simmer JP (2005) Proteomics and genetics of dental enamel. Cells Tissues Organs 181: 219-231. 
Iizuka S, Kudo Y, Yoshida M, Tsunematsu T, Yoshiko Y, Uchida T, Ogawa I, Miyauchi M, Takata T (2011) Ameloblastin regulates osteogenic differentiation by inhibiting Src kinase via crosstalk between integrin $\beta 1$ and CD63. Mol Cell Biol 31: 783-792.

Irie K, Zalzal S, Ozawa H, McKee MD, Nanci A (1998) Morphological and immunocytochemical characterization of primary osteogenic cell cultures derived from fetal rat cranial tissue. Anat Rec 252: 554-567.

Kawasaki K, Weiss KM (2003) Mineralized tissue and vertebrate evolution: the secretory calcium-binding phosphoprotein gene cluster. Proc Natl Acad Sci USA 100: 4060-4065.

Krebsbach PH, Lee SK, Matsuki Y, Kozak CA, Yamada KM, Yamada Y (1996) Full-length sequence, localization, and chromosomal mapping of ameloblastin. A novel toothspecific gene. J Biol Chem 271: 4431-4435.

McKee MD, Nanci A, Landis WJ, Gotoh Y, Gerstenfeld LC, Glimcher MJ (1991) Effects of fixation and demineralization on the retention of bone phosphoprotein and other matrix components as evaluated by biochemical analyses and quantitative immunocytochemistry. J Bone Miner Res 6: 937-945.

Moffatt P, Salois P, St-Amant N, Gaumond MH, Lanctôt C (2004) Identification of a conserved cluster of skin-specific genes encoding secreted proteins. Gene 334: 123-131.

Moffatt P, Gaumond MH, Salois P, Sellin K, Bessette MC, Godin E, de Oliveira PT, Atkins GJ, Nanci A, Thomas G (2008) Bril: a novel bone-specific modulator of mineralization. J Bone Miner Res 23: 1497-1508.

Nanci A, Zalzal S, Gotoh Y, McKee MD (1996) Ultrastructural characterization and immunolocalization of osteopontin in rat calvarial osteoblast primary cultures. Microsc Res Tech 33: 214-231.

Nanci A, Zalzal S, Lavoie P, Kunikata M, Chen WY, Krebsbach PH, Yamada Y, Hammarström L, Simmer JP, Fincham AG, Snead ML, Smith CE (1998) Comparative immunochemical analyses of the developmental expression and distribution of ameloblastin and amelogenin in rat incisors. J Histochem. Cytochem. 46: 911-934.

Nanci A, Wazen RM, Zalzal SF, Fortin M, Goldberg HA, Hunter GK, Ghitescu DL (2004) A tracer study with systemically and locally administered dinitrophenylated osteopontin. J Histochem Cytochem 52: 1591-1600.

Pereira BP, Zhou Y, Gupta A, Leong DT, Aung KZ, Ling L, Pho RW, Galindo M, Salto-Tellez M, Stein GS, Cool SM, van Wijnen AJ, Nathan SS (2009) Runx2, p53, and $\mathrm{pRB}$ status as diagnostic parameters for deregulation of osteoblast growth and differentiation in a new prechemotherapeutic osteosarcoma cell line (OS1). J Cell Physiol 221: 778-788.

Raggatt LJ, Partridge NC (2010) Cellular and molecular mechanisms of bone remodeling. J Biol Chem 285: 25103 25108.

Sakai Y, Balam TA, Kuroda S, Tamamura N, Fukunaga T, Takigawa M, Takano-Yamamoto T (2009) CTGF and apoptosis in mouse osteocytes induced by tooth movement. J Dent Res 88: 345-350.
Schmittgen TD, Livak KJ (2008) Analyzing real-time PCR data by the comparative $\mathrm{C}_{\mathrm{T}}$ method. Nat Protoc 3: 1101-1108.

Schroeder HE (1991) The rate of the eruption of human teeth. A review. Schweiz Monatsschr Zahnmed 101: 279284.

Shapiro JL, Wen X, Okamoto CT, Wang HJ, Lyngstadaas SP, Goldberg M, Snead ML, Paine ML (2007) Cellular uptake of amelogenin, and its localization to CD63, and Lamp1-positive vesicles. Cell Mol Life Sci 64: 244-256.

Sire JY, Davit-Béal T, Delgado S, Gu X (2007) The origin and evolution of enamel mineralization genes. Cells Tissues Organs 186: 25-48.

Smith CE, Wazen R, Hu Y, Zalzal SF, Nanci A, Simmer JP, Hu JC (2009) Consequences for enamel development and mineralization resulting from loss of function of ameloblastin or enamelin. Eur J Oral Sci 117: 485-497.

Spahr A, Lyngstadaas SP, Slaby I, Pezeshki G (2006) Ameloblastin expression during craniofacial bone formation in rats. Eur J Oral Sci 114: 504-511.

Stanford CM, Jacobson PA, Eanes ED, Lembke LA, Midura RJ (1995) Rapidly forming apatitic mineral in an osteoblastic cell line (UMR 106-01 BSP). J Biol Chem 270: 9420-9428.

Tamburstuen MV, Reppe S, Spahr A, Sabetrasekh R, Kvalheim G, Slaby I, Syversen U, Lyngstadaas SP, Reseland JE (2010) Ameloblastin promotes bone growth by enhancing proliferation of progenitor cells and by stimulating immunoregulators. Eur J Oral Sci 118: 451459.

Tamburstuen MV, Reseland JE, Spahr A, Brookes SJ, Kvalheim G, Slaby I, Snead ML, Lyngstadaas SP (2011) Ameloblastin expression and putative autoregulation in mesenchymal cells suggest a role in early bone formation and repair. Bone 48: 406-413.

Wang D, Christensen K, Chawla K, Xiao G, Krebsbach PH, Franceschi RT (1999) Isolation and characterization of MC3T3-E1 preosteoblast subclones with distinct in vitro and in vivo differentiation/mineralization potential. J Bone Miner Res 14: 893-903.

Wazen RM, Moffatt P, Zalzal SF, Daniel NG, Westerman KA, Nanci A (2006) Local gene transfer to calcified tissue cells using prolonged infusion of a lentiviral vector. Gene Ther 13: 1595-1602.

Wazen RM, Moffatt P, Zalzal SF, Yamada Y, Nanci A (2009) A mouse model expressing a truncated form of ameloblastin exhibits dental and junctional epithelium defects. Matrix Biol 28: 292-303.

\section{Discussion with Reviewer}

Reviewer II: Have you tried different concentrations of the AMBN virus?

Authors: For each cell line, we have tested the effect of AMBN viral vectors at different doses ranging from $1 \times 10^{5}$ to $6 \times 10^{6}$ (in triplicates). Since we did not see a significant difference at any viral dose and to avoid repetition, we chose to show only one representative experiment for each cell line. 
Reviewer II: Couldn't you use a dental epithelial cell line that will eventually show differences after AMBN virus infection as a control?

Authors: A dental epithelium cell line could indeed be used as a control to show the effect of over expressing AMBN. However, the fact remains that after infection primary osteogenic cells, MC3T3-E1 and SaOS2 cells do express
AMBN and that such expression under the conditions we have used does not result in any enhanced osteogenic activity. Indeed, our animal studies confirm that AMBN is not needed for normal bone formation and repair to take place. This, however, would not rule out the possibility that large supraphysiological doses of AMBN may have a pharmacological effect. 